\title{
Postsynaptic Injection of Calcium-Independent Phospholipase A2 Inhibitors Selectively Increases AMPA Receptor-Mediated Synaptic Transmission
}

\author{
Fannie St-Gelais, ${ }_{1}^{1}$ Caroline Ménard ${ }^{2}$ Patrice Congar, ${ }^{1}$ Louis-Eric Trudeau, ${ }^{1}$ \\ and Guy Massicotte ${ }^{1,2 *}$
}

\begin{abstract}
The calcium-independent form of phospholipase A2 (iPLA2), an enzyme known to generate arachidonic acid (AA), was recently identified as the predominant constitutive phospholipase in the hippocampus. The present study shows that the iPLA2 inhibitor bromoenol lactone, when introduced into hippocampal CA1 pyramidal cells through a patch pipette, generated a dose-dependent increase in the amplitude of $\alpha$-amino-3-hydroxy-5-methylisoxazole-4-propionate (AMPA) receptor-mediated excitatory postsynaptic currents (EPSCs). The iPLA2 inhibitor by itself interfered with neither paired pulse facilitation nor $\mathrm{N}$-methyl-D-aspartate (NMDA) receptor-mediated EPSCs, suggesting that its influence on synaptic transmission is postsynaptic in origin and specific to the AMPA subtype of glutamate receptors. Comparable results were obtained with palmitoyl trifluoromethyl ketone, a second structurally distinct iPLA2 inhibitor. The ability of iPLA2 inhibitors to increase AMPA receptor-mediated currents was also reproduced by MK-866, an inhibitor recognized to interfere with the generation of 5-lipoxygenase by-products of AA. At the biochemical level, we found that AMPA, but not NMDA glutamate receptor subunits, were upregulated in rat brain sections pre-incubated with the iPLA2 inhibitors. Collectively, these results provide the first experimental evidence that constitutive iPLA2 and/or its metabolites play an important role in the postsynaptic modulation of neurotransmission in CA1 pyramidal cells of the hippocampus. (c) 2004 Wiley-Liss, Inc.
\end{abstract}

KEY WORDS: phospholipase A2; AMPA receptor; glutamate; patch clamp; 5-lipoxygenase; hippocampus

\section{INTRODUCTION}

Phospholipase A2 (PLA2) belongs to a superfamily of enzymes that preferentially catalyze the hydrolysis of phospholipids into fatty acids, such as

\footnotetext{
${ }^{1}$ Département de Pharmacologie, Faculté de Médecine, Université de Montréal, Montréal, Québec, Canada; ${ }^{2}$ Département de Chimie-Biologie, Université du Québec à Trois-Rivières, Trois-Rivières, Québec, Canada Abbreviations used: AA, arachidonic acid; AACOCF3, arachidonyl trifluoromethyl ketone; ACSF, artificial cerebrospinal fluid; AMPA, $\alpha$-amino-3-hydroxy5-methylisoxazole-4-propionate; BEL, bromoenol lactone; COX, cyclooxygenase; CPLA2, calcium-dependent phospholipase A2; DMSO, dimethylsulfoxide; EPSC, excitatory postsynaptic current; iPLA2, calcium-independent phospholipase A2; LO, lipoxygenase; LTD, long-term depression; LTP, long-term potentiation; NMDA, N-methyl-D-aspartate; PACOCF3, palmitoyl trifluoromethyl ketone; PBS, phosphate-buffered saline; PLA2, phospholipase A2; PPF, paired-pulse facilitation.

Grant sponsor: Natural Sciences and Engineering Research Council (NSERC) of Canada.

*Correspondence to: Dr. Guy Massicotte, Département de Chimie-Biologie, Université du Québec à Trois-Rivières, 3351, Boul. des Forges, C.P. 500 Trois-Rivières, Québec, Canada G9A 5H7. E-mail: guy_massicotte@uqtr.ca Accepted for publication 28 April 2003

DOI 10.1002/hipo.10176

Published online 6 January 2004 in Wiley InterScience (www.interscience. wiley.com).
}

arachidonic acid (AA) and lysophospholipids. These products can act as cellular second messengers and be further metabolized by intracellular enzymes into prostaglandins, leukotrienes, hydroxyeicosatetraenoic acid, and platelet-activating factor (PAF), which are known to have a number of cellular functions (Winstead et al., 2000; Dessen, 2000). In the brain, several investigations have demonstrated that stimulation of calcium-dependent forms of PLA2 (cPLA2), as well as generation of lipoxygenase (LO) by-products of AA can exert both pre- and postsynaptic actions during the expression of long-term potentiation (LTP) and depression (LTD), two electrophysiological models of synaptic plasticity thought to subserve learning and memory processes. In contrast, biochemical studies suggest that cPLA2-induced regulation of $\alpha$-amino-3-hydroxy-5-methylisoxazole-4-propionate (AMPA) glutamate receptor conformation might be an important mechanism for the expression of synaptic plasticity (Massicotte, 2000). Recently, it was found that the calcium-independent form of PLA2 (iPLA2) represents the predominant constitutive phospholipase activity in several brain structures, especially in the hippocampus (Wolf et al., 1995; Yang et al., 1999). Although little is known about iPLA2 functions in neurons, a growing body of evidence points to its possible involvement in learning and memory (Fujita et al., 2000) as well as in neurodegenerative disorders, such as Alzheimer's disease and schizophrenia (Ross et al., 1998, 1999).

In several cell types, iPLA2 is recognized to perform a key role in cellular fatty acid uptake and remodeling of membrane phospholipids (Balsinde and Dennis, 1997). Furthermore, recent reports have suggested that constitutive iPLA2 activity might contribute to membranetrafficking events required along both endocytic and exocytic pathways. In particular, the effects of iPLA2 inhibitors on membrane fusion (Mayorga et al., 1993; Takuma and Ichida, 1997) and tubule formation in the Golgi complex (de Figueiredo et al., 1998; Kuroiwa et al., 2001) underline the potential significance of iPLA2 in membrane-trafficking processes. Recent investigations have demonstrated that membrane-trafficking events are important mechanisms contributing to the surface expression of AMPA receptors in hippocampal neurons (Man et al., 2000; Broutman and Baudry, 2001), raising the intriguing possibility that these receptors might also be under the influence of iPLA2 activity. In that perspec- 
tive, patch-clamp recording experiments were performed in CA1 pyramidal neurons of rat hippocampal slices to study the impact of $\mathrm{iPLA}_{2}$ inhibition on glutamate receptor-mediated synaptic transmission. Specifically, we explored this possibility by applying, directly into postsynaptic cells, a number of agents recognized to interfere with iPLA2 activity and AA metabolism. We also investigated the effects of iPLA2 inhibition on glutamate receptor subunit properties in rat brain sections.

\section{MATERIALS AND METHODS}

\section{Slice Preparation}

Hippocampal slices were prepared from 15- to 30-day-old Sprague-Dawley rats anesthetized with isoflurane and decapitated. Their brains were removed rapidly and placed in ice-cold artificial cerebrospinal fluid (ACSF; $1-4^{\circ} \mathrm{C}$ ), which consisted of (in $\mathrm{mM}$ ): $\mathrm{NaCl}$ 126, KCl 3.5, $\mathrm{CaCl}_{2} 2.0, \mathrm{MgCl}_{2}$ 1.3, $\mathrm{NaHPO}_{4}$ 1.2, $\mathrm{NaHCO}_{3} 25$, glucose 11 (pH 7.3; 300 mOsm) continuously bubbled with $95 \% \mathrm{O}_{2}$ and $5 \% \mathrm{CO}_{2}$. The brains were rapidly trimmed down to a block containing the hippocampus; transverse slices $(400 \mu \mathrm{m})$ were cut in the same ice-cold ACSF with a vibratome (Series 1000, Vibratome Co., St. Louis, MO). The CA3 region was removed surgically to avoid the propagation of recurrent epileptiform activities, and the slices were transferred to a holding chamber containing bubbled ACSF at room temperature for at least an hour before recording. The slices were used within $6 \mathrm{~h}$ after their preparation, were transferred, as needed, to a recording chamber, and perfused continuously $(2 \mathrm{ml} / \mathrm{min})$ at a regulated temperature of $33^{\circ} \mathrm{C}$ with ACSF containing picrotoxin $(0.1 \mathrm{mM})$.

\section{Electrophysiology}

Whole-cell recordings were made with a PC-505A patch-clamp amplifier from Warner Instrument Corporation (Hamdem, CT), filtered at $1 \mathrm{kHz}$ and digitized at $5 \mathrm{kHz}$ with a Digidata 1320 converter and Clampex 8 software (Axon Instruments, Union City, CA). Recordings were obtained from CA1 pyramidal neurons, using patch pipettes $(5-6 \mathrm{M} \Omega$ ) filled with the following internal solution (in $\mathrm{mM}$ ): $\mathrm{CsMeSo} 3 \mathrm{120}, \mathrm{CsCl} 20$, HEPES 10, MgATP 4, $\mathrm{Na}_{3}$ GTP 0.3, EGTA 0.2, phosphocreatine 10, pH 7.3, and with osmolarity adjusted to $300 \mathrm{mOsm}$ (VAPRO 5520, Wescor, Logan, UT). CA1 pyramidal neurons were patch-clamped in whole-cell configuration under visual guidance with an Olympus BX50WI microscope equipped for IR-DIC videomicroscopy. The cells were voltage-clamped at a holding potential of $-70 \mathrm{mV}$. To evoke synaptic responses, stimuli $(0.05 \mathrm{~Hz}, 100 \mu \mathrm{s})$ were delivered from bipolar electrodes placed in the stratum radiatum to excite Schaffer collaterals. The intensity of stimulation ranged from 1 to $3 \mathrm{~mA}$ and was adjusted to evoke excitatory postsynaptic currents (EPSCs) with an amplitude of $\sim 50 \mathrm{pA}$ at the beginning of the experiment. For paired-pulse facilitation (PPF) experiments, paired identical stimuli (100 $\mu \mathrm{s}$, interstimuli interval of $75 \mathrm{~ms}$ ) were delivered at the same frequency of $0.05 \mathrm{~Hz}$. As a standard protocol after the establishment of whole-cell configuration, a 5-min baseline of "single-pulse" stimulations was followed by 5 min of paired-pulse stimulations; single-pulse synaptic responses were evoked at a frequency of $0.05 \mathrm{~Hz}$ for $30 \mathrm{~min}$, and a second protocol of paired-pulse stimulations was then applied (5 min). Single-pulse synaptic responses were finally evoked at a frequency of $0.05 \mathrm{~Hz}$ for the last $30 \mathrm{~min}$. N-methyl-D-aspartate (NMDA) receptor-mediated EPSCs were recorded by reducing the $\mathrm{Mg}^{2+}$ concentration in ACSF to $0.5 \mathrm{mM}$ and by adding cyano-7-nitroquinoxaline-2,3-dione $(20 \mu \mathrm{M})$ to block the AMPA subtype of glutamate receptors.

\section{Data Analysis}

For each experiment, the amplitude of evoked EPSCs was normalized to the mean EPSC amplitude measured during the baseline recording period corresponding to the first $5 \mathrm{~min}$ after membrane break-in. These values are reported as percentage changes from baseline. Values given in the text are means \pm SEM, and statistical significance was assessed by Wilcoxon tests, with a probability value of $P<0.05$ as an indication of significant differences. Representative traces are averages of 10 sweeps.

\section{Electrophoresis and Immunoblotting}

Horizontal $30-\mu \mathrm{m}$ rat brain sections were cut in a cryostat and thaw-mounted in chrome-alum gelatin-coated slides. Adjacent sections were preincubated for $60 \mathrm{~min}$ in $50 \mathrm{ml}$ of Tris-acetate buffer (100 mM, pH 7.4) containing $100 \mu \mathrm{M}$ EGTA at $35^{\circ} \mathrm{C}$ with or without different concentrations of iPLA2 inhibitors. Tissue was collected in Tris-acetate buffer $(50 \mathrm{mM}, \mathrm{pH} 7.4)$ containing $100 \mu \mathrm{M}$ EGTA and several protease inhibitors (leupeptin $5 \mu \mathrm{M}$, phenylmethylsulfonyl fluoride (PMSF) $200 \mu \mathrm{M}$, and N-tosyl-Lphenylalanine chloromethyl ketone $1 \mu \mathrm{g} / \mathrm{ml}$ ). The tissue was then homogenized with a glass-Teflon homogenizer. Western blot analysis was conducted on homogenates obtained from both control and PLA2 inhibitor-treated sections. Aliquots of homogenates were subjected to SDS-PAGE (8\% polyacrylamide), according to the method of Laemmli (1970). Proteins were transferred onto nitrocellulose membranes, as described previously (Towbin et al., 1979). To block nonspecific sites, the membranes were first incubated for $1 \mathrm{~h}$ at room temperature in phosphate-buffered saline (PBS) containing 5\% dry nonfat milk. They were then incubated with primary antibodies directed against glutamate receptor subunits GluR1 $(0.5 \mu \mathrm{g} / \mathrm{ml})$, GluR2/3 $(0.5 \mu \mathrm{g} / \mathrm{ml})$, NR1 $(0.5 \mu \mathrm{g} / \mathrm{ml})$ and NR2A $(0.5 \mu \mathrm{g} / \mathrm{ml})$ (Santa Cruz Biotechnology, Santa Cruz, CA) in PBS containing nonfat milk. Bands corresponding to GluR and NR subunits were detected with an alkaline phosphatase-conjugated secondary antibody (Roche Molecular Biochemicals, Laval, Québec). The relative optical density of the immunoreactive bands was quantified with a digital imaging system (Imaging Research, MCID, St. Catherines, Ontario). For statistical analysis, ANOVA was followed by Scheffé's post hoc analysis.

\section{Drugs}

The iPLA2 inhibitors bromoenol lactone (BEL, $\mathrm{IC}_{50}, 0.1-1.0$ $\mu \mathrm{M}$ ) and palmitoyl trifluoromethyl ketone (PACOCF3, IC ${ }_{50}, 3.8$ $\mu \mathrm{M})$, the cPLA2 inhibitor arachidonyl trifluoromethyl ketone 
(AACOCF3, $\mathrm{IC}_{50}, 8 \mu \mathrm{M}$ ), the cyclooxygenase inhibitor indomethacin $\left(\mathrm{IC}_{50}, 0.1 \mu \mathrm{M}\right)$, the $12-\mathrm{LO}$ inhibitor baicalein $\left(\mathrm{IC}_{50}\right.$, $0.2-9.5 \mu \mathrm{M})$ and the 5-LO inhibitor MK-886 ( $\left.\mathrm{IC}_{50}, 1 \mu \mathrm{M}\right)$ were purchased from BIOMOL Research Laboratories (Plymouth Meeting, PA). All other chemical reagents were obtained from the Sigma Chemical Co. (St. Louis, MO). Stock solutions of the inhibitors were prepared in dimethylsulfoxide (DMSO) and stored at $-20^{\circ} \mathrm{C}$. The inhibitors were added to the intra-pipette solutions such that the final concentration of DMSO was $0.1 \%$. In control experiments (not shown), we determined that, by itself, intra-pipette DMSO at this concentration had no effect on EPSC amplitude.

\section{RESULTS}

\section{iPLA2 Inhibition Increases AMPA Receptor- Mediated EPSCs}

We first examined the effects of loading CA1 pyramidal cells with the inhibitor BEL, which is known to preferentially inactivate iPLA2. As shown in Figure 1A, introduction of $10 \mu \mathrm{M}$ BEL into the pipette solution caused a gradual and pronounced increase in EPSC amplitude. The amplitude of AMPA receptor-mediated EPSCs was enhanced by $72 \pm 15 \%$ after 30 min of recording, relative to the baseline value estimated during the first $5 \mathrm{~min}$ of the experiments ( $\mathrm{n}=5$; Wilcoxon test, $P<0.05$ ) (Fig. $1 \mathrm{~A}$ ), an effect that remained stable afterward. Changes in AMPA receptor EPSCs induced by BEL were dose-dependent, with a maximal impact occurring at $30 \mu \mathrm{M}$ (Fig. 1B); at this concentration, EPSC amplitudes reached an average value of $160 \pm 30 \%(\mathrm{n}=8$, Wilcoxon test, $P<0.05)$ over baseline. As a control, we performed experiments in which whole-cell recordings were made in the absence of the inhibitor. Under such conditions, the amplitude of AMPA receptor EPSCs was not altered during the course of the experiments ( $7 \pm 4 \%$ of baseline after $30 \mathrm{~min} ; \mathrm{n}=7$ ) (Fig. 1A). Finally, to confirm our main findings, we used a second iPLA2 inhibitor from a different chemical family. We found that PACOCF3 (10 $\mu \mathrm{M})$, a drug that is also known to inhibit iPLA2, increased EPSC amplitude by $152 \pm 68 \%$ when introduced in the pipette solution (n $=4$; Wilcoxon test, $P<0.05$ ) (data not shown).

It has been reported that calcium-dependent forms of PLA2 (cPLA2), in addition to iPLA2, are present in the brain. We therefore conducted experiments to determine whether inhibition of cPLA2 can also affect AMPA receptor EPSCs. In this set of experiments, CA1 neurons were loaded with AACOCF3, a potent inhibitor cPLA2 activities. In contrast to BEL and PACOCF3, introduction of $10 \mu \mathrm{M}$ AACOCF3 into the pipette solution did not modify AMPA receptor EPSC amplitude during the course of the experiments $(2 \pm 7 \%, \mathrm{n}=7$; Wilcoxon test, $P<0.05$, Fig. $1 \mathrm{~A}, \mathrm{~B})$. However, internal solutions containing higher concentrations of AACOCF3 $(60 \mu \mathrm{M})$ were found to generate a significant increase in EPSC amplitude ( $75 \pm 27 \%$; $\mathrm{n}=5$, Wilcoxon test, $P<0.05$, Fig. 1B) compared to baseline. This observation is consistent with biochemical assays, indicating that the inhibitor also prevents iPLA2 activities when used at such high concentrations (Dessen,

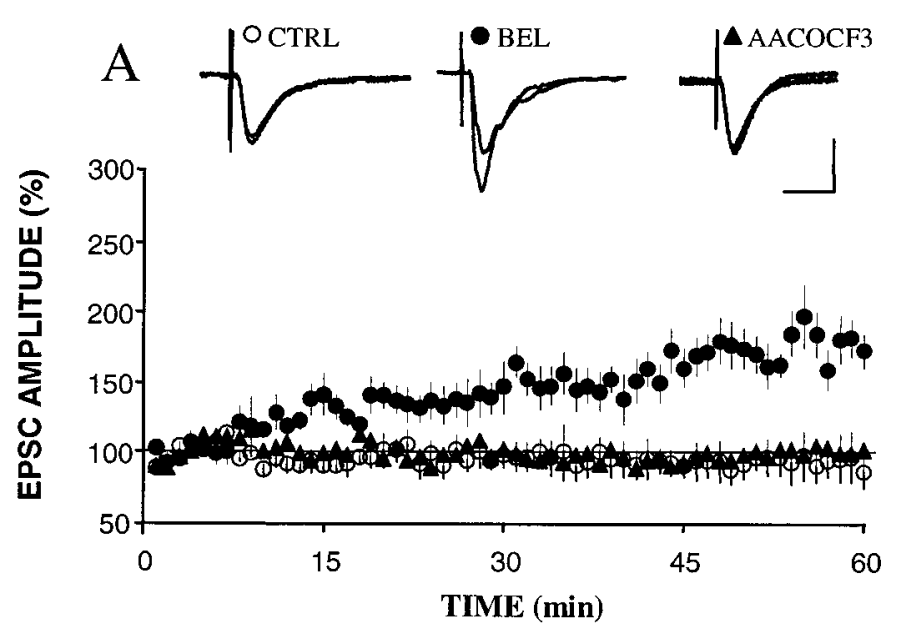

\section{B}

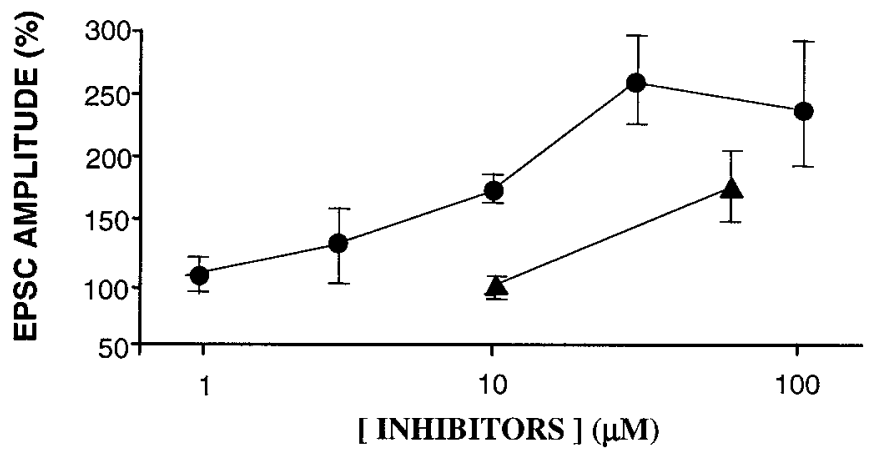

FIGURE 1. Bromoenol lactone (BEL) increases evoked $\alpha$-amino3-hydroxy-5-methylisoxazole-4-propionate (AMPA)-mediated responses in CA1 neurons. A: AMPA receptor-mediated excitatory postsynaptic currents (EPSCs), elicited by stimulation of the Schaffer commissural pathway, were monitored after introduction of $10 \mu \mathrm{M}$ BEL (filled circles, $\mathbf{n}=8$ ) or AACOCF3 (filled triangles, $\mathbf{n}=7$ ) into the micropipette solution. Control experiments (open circles, $\mathbf{n}=7$ ) were performed with vehicle only. The data represent EPSC amplitude and are expressed as percentages of the average response recorded during the 5-min baseline period. EPSC traces monitored $5 \mathrm{~min}$ and $30 \mathrm{~min}$ after whole-cell recording was established are shown above the graph. Each sample trace is an average of 10 consecutive responses. B: Dose-response relationship of the enhancement in AMPA receptormediated EPSC amplitude by BEL (filled circles, $n=5$ ) and AACOCF3 (filled triangles, $n=4$ ). The data are presented as percentage increases in EPSC amplitude obtained after $30 \mathrm{~min}$ of recording, relative to the 5 -min baseline period (mean $\pm S E M$ of five experiments). Scale bar $=40 \mathrm{pA} / 25 \mathrm{~ms}$ in A.

2000). In summary, based on their relative potency in suppressing iPLA2 in vitro, we conclude that the effects of the two PLA2 inhibitors on AMPA-mediated responses may be ascribed to depression of constitutive iPLA2 activity.

\section{iPLA2 Acts Postsynaptically}

The results reported thus far indicate that fast excitatory synaptic transmission in CA1 pyramidal cells is under the influence of iPLA2 activity. These data can be explained either by an increase in 

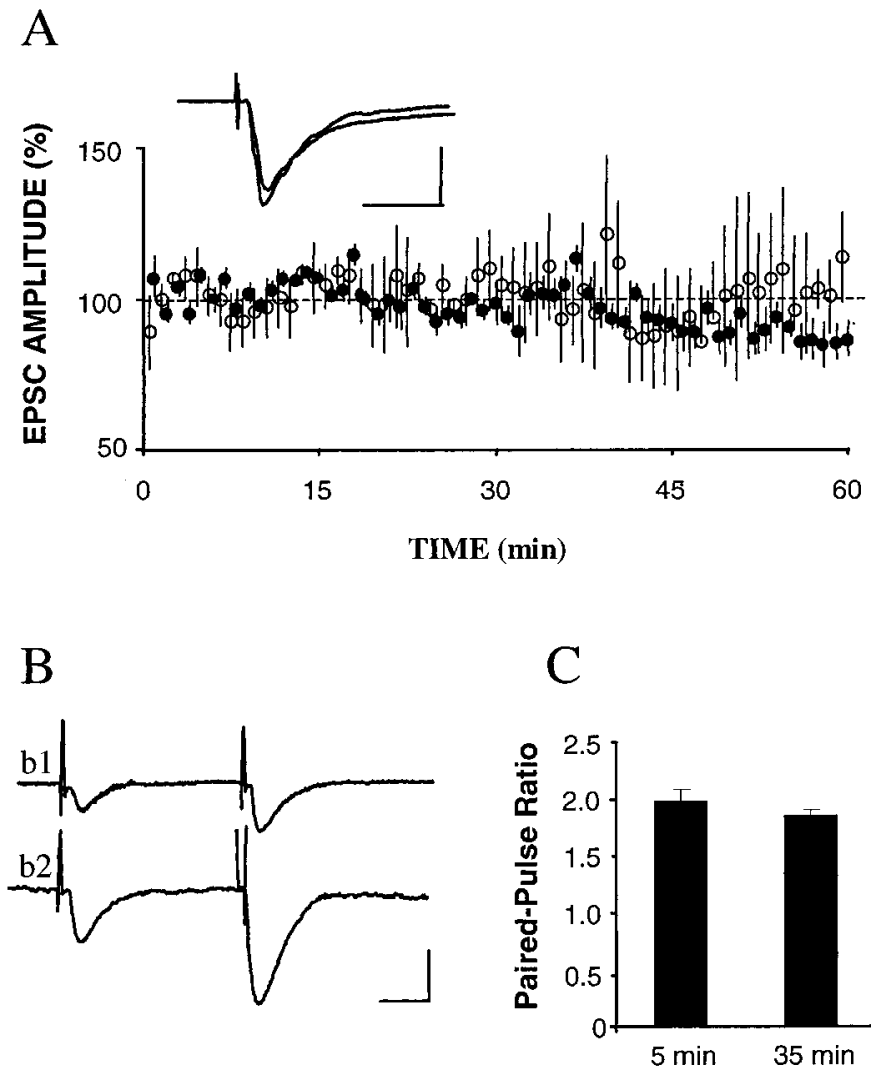

FIGURE 2. Bromoenol lactone (BEL) produces no change in NMDA-mediated responses and paired-pulse facilitation. A: NMDA receptor-mediated EPSCs, elicited by stimulation of the Schaffer commissural pathway, were monitored after introduction of $30 \mu \mathrm{M}$ BEL (filled circles, $n=5$ ). Control experiments were performed with vehicle only (open circles, $n=5$ ). The data represent excitatory postsynaptic currents (EPSCs) amplitude and are expressed as percentages of the average response recorded during the 5-min baseline period. EPSC traces monitored 5 and $30 \mathrm{~min}$ after whole-cell recording was established are shown above the graph. Each sample trace is an average of 10 consecutive responses. Scale bars $=25$ pA/60 ms. B: Representative traces from a paired-pulse facilitation experiment. The upper traces (b1) show paired responses during the first $5 \mathrm{~min}$ of recording while the lower traces (b2) depict paired responses recorded $30 \mathrm{~min}$ after whole-cell recording was established. C: Summary histogram demonstrating that paired-pulse facilitation was not modified when the intra-pipette solution contained $30 \mu \mathrm{M}$ BEL (mean \pm SEM of five experiments). The degree of facilitation at a 75-ms interpulse interval was calculated as the percentage increase in the amplitude of the second EPSC compared to the first. Scale bars $=25 \mathrm{pA} / 25 \mathrm{~ms}$ in B.

the presynaptic release of glutamate and/or by changes in postsynaptic receptor properties. To investigate these possibilities, we first designed experiments to determine whether the NMDA receptormediated component of synaptic transmission in CA1 cells loaded with BEL is also increased. If we hypothesize that the effect involves a presynaptic mechanism, loading of CA1 cells with the iPLA2 inhibitor should result in enhancement of both NMDAand AMPA-mediated EPSCs. In contrast to AMPA responses, we observed that the evoked NMDA-mediated EPSCs remained stable during recordings (Fig. 2A). In fact, neither $10 \mu \mathrm{M}$ nor $30 \mu \mathrm{M}$
BEL caused any significant change in NMDA receptor-mediated EPSC amplitudes which were respectively $14 \pm 8 \%(\mathrm{n}=5$; Wilcoxon test, $P>0.05)$ and $18 \pm 13 \%(\mathrm{n}=5$; Wilcoxon test, $P<$ $>0.05$ ) of baseline value, when estimated after $30 \mathrm{~min}$ of recording (Fig. 2A). This finding indicates that BEL-induced changes in synaptic transmission require selective postsynaptic enhancement of AMPA receptor function, rather than alterations in presynaptic release of glutamate. Consistently and as predicted from a predominantly postsynaptic mechanism, no changes in PPF were seen in CA1 pyramidal cells loaded with BEL (Fig. 2B).

\section{Possible Involvement of 5-LO Metabolites}

Given the results with BEL and evidence that AMPA receptors are under the influence of iPLA2 activity, we wondered whether interference with the formation of lipid by-products of AA would generate similar effects. To test this idea, we used inhibitors that are known to block cyclooxygenase (COX), 5- and 12-LO pathways of AA metabolism. As can be seen in Figure 3A, neither indomethacin (COX inhibitor) nor baicalein (12-LO inhibitor), introduced in the patch pipette, produced modifications in evoked AMPA-mediated synaptic responses. However, in experiments with MK-886 (a 5-LO inhibitor), we observed that AMPA receptor-mediated EPSC amplitude gradually increased in size and reached a maximum of $170 \pm 60 \%$ over baseline $(\mathrm{n}=9$; Wilcoxon test, $P<$ 0.05 ) after $30 \mathrm{~min}$ of recording. These results suggest an important role of 5-LO metabolites of AA in the postsynaptic modulation of glutamatergic neurotransmission by iPLA2.

\section{iPLA2 Inhibition Increases GluR Immunoreactivity in Rat Brain Sections}

The precise cellular mechanisms by which iPLA2 inhibition upregulates AMPA receptor function in CA1 hippocampal neurons remain to be determined. In the present investigation, we examined the possibility that the biochemical properties of AMPA receptors are under the control of iPLA2 activity. Rat brain sections were preincubated in the presence and absence of increasing concentrations of BEL for $60 \mathrm{~min}$. After preincubation, they were homogenized and samples were immunoblotted with antibodies against the C-terminal domains of GluR1 or GluR2/3, as reported previously (Bi et al., 1997, 1998). As illustrated in Figure 4, Western blotting experiments indicated a dose-dependent increase of GluR1 and GluR2/3 immunoreactivity, with maximal augmentation of about $100 \%$ over control values at concentrations of 3 to 10 $\mu \mathrm{M}$ BEL. A similar result was observed in the presence of the other iPLA2 inhibitor, PACOCF3 $(3 \mu \mathrm{M})$; at this concentration, GluR1 immunoreactivity was increased by $30 \pm 4 \%(n=6$; data not shown). Consistent with the electrophysiological experiments, we found that no significant differences in the NR1 and NR2A subunits of NMDA receptors were detected in brain homogenates prepared from control and BEL-treated sections (Fig. 4), reinforcing the notion that apparent changes in synaptic transmission generated by this iPLA2 inhibitor are due to selective alterations in AMPA receptor properties. 

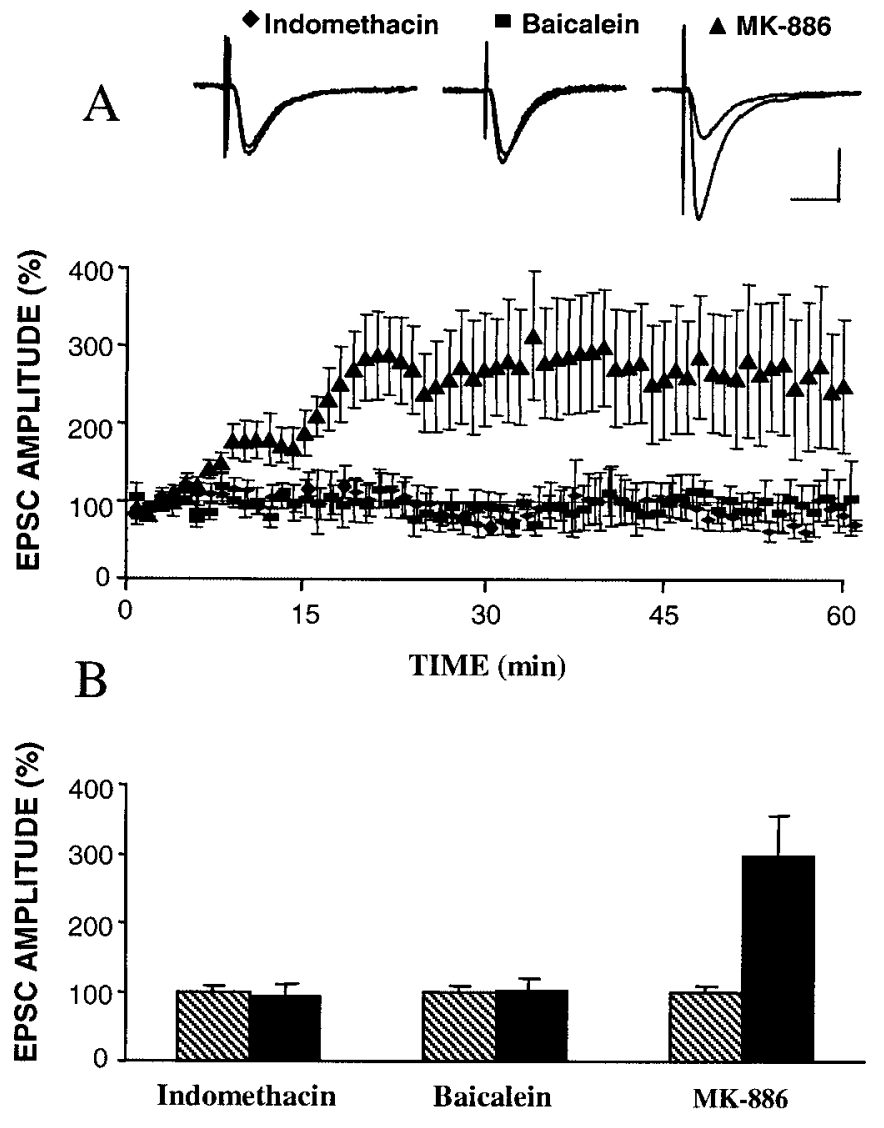

FIGURE 3. Inhibition of 5-LO metabolites of arachidonic acid (AA) generates an augmentation in $\alpha$-amino-3-hydroxy-5-methylisoxazole-4-propionate (AMPA)-mediated responses. AMPA receptormediated excitatory postsynaptic currents (EPSCs), elicited by stimulation of the Schaffer commissural pathway, were monitored after the introduction of $30 \mu \mathrm{M}$ indomethacin $(n=5)$, baicalein $(n=5)$ and MK-886 $(n=9)$ into the patch pipette solution. The data represent EPSC amplitude and are expressed as percentages of the average response recorded during the 5 -min baseline period. EPSC traces monitored $5 \mathrm{~min}$ and $30 \mathrm{~min}$ after whole-cell recording was established are shown above the graph. Each sample trace is an average of 10 consecutive responses. Scale bars: 40 pA/30 ms. Summary histogram showing that AMPA responses were only altered when the 5-LO inhibitor MK-886 was included in the intra-pipette solution. The data are presented as percentage increases in EPSC amplitude obtained after $30 \mathrm{~min}$ of recording, relative to the 5 -min baseline period.

\section{DISCUSSION}

The present studies demonstrate for the first time that synaptic transmission in the rat hippocampus is under the influence of constitutive iPLA2 activities. Specifically, our results show that the injection of iPLA2 inhibitors into postsynaptic CA1 pyramidal neurons generated a gradual and robust enhancement in the amplitude of AMPA receptor-mediated EPSCs. This regulatory process appears to be specific to AMPA receptors relative to NMDAmediated receptors and occurs without gross changes in transmitter release at presynaptic sites, as indicated by the apparent preservation of PPF in BEL-injected cells. The effect reported also appears to be dependent on iPLA2 inhibition, since we found that

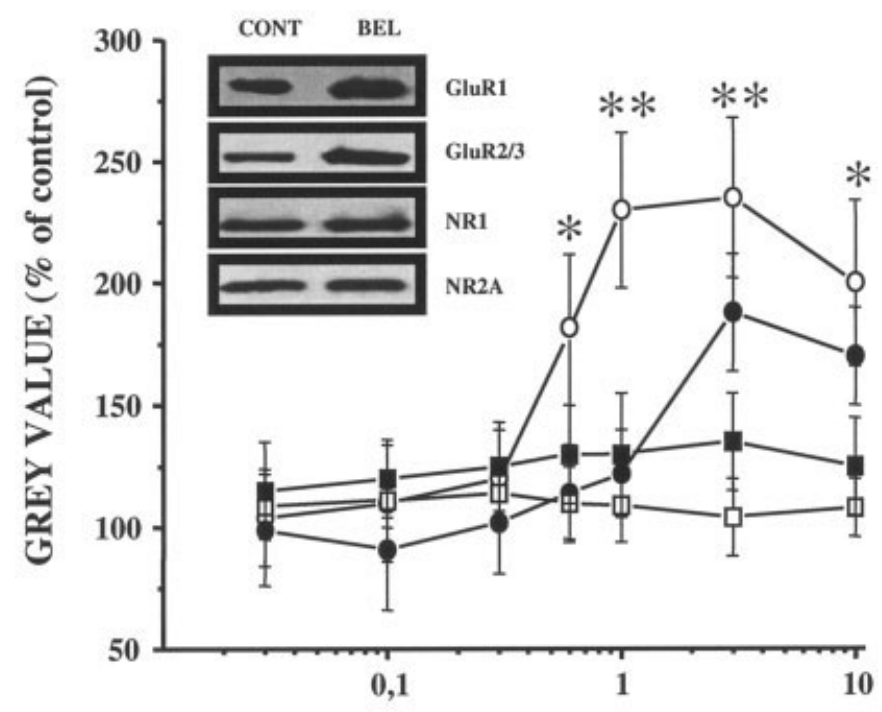

$[\mathrm{BEL}](\mu \mathrm{M})$

FIGURE 4. Bromoenol lactone (BEL) selectively alters GluR immunoreactivity in rat brain sections. Adjacent horizontal sections at the level of the dorsal hippocampus were preincubated at $35^{\circ} \mathrm{C}$ for $1 \mathrm{~h}$ in the absence or presence of increasing concentrations $(0.01-10 \mu \mathrm{M})$ of BEL. Homogenates of rat brain sections were prepared, and Western blots performed by using antibodies against the $\mathrm{C}$-terminal domain of GluR1 (open circles), GluR2/3 (closed circles), NR1 (open squares) and NR2A (closed squares). Blots were digitized, and the intensity of the 105-kDa bands was quantified (grey values). Representative Western blots showing BEL-induced modulation of the GluR1 subunits are presented within the graph. The results are expressed as percentage of control values found in homogenates and represent the means \pm SEM of five experiments. ${ }^{*} \mathbf{P}<0.05$; ${ }^{* *} \mathbf{P}<$ 0.05, compared with control values (Scheffe's test).

AACOCF3, a very potent cPLA2 inhibitor, was less consequential in changing AMPA-mediated synaptic transmission, thus making it very unlikely that the action of BEL or PACOCF3 resulted from cPLA2 inhibition. This interpretation is compatible with biochemical experiments indicating that the main constitutive PLA2 activity in the hippocampus is calcium-independent in nature (Wolf et al., 1995; Yang et al., 1999). Indeed, the present electrophysiological findings suggest a new biochemical model in which constitutive iPLA2 activity and/or its metabolites might negatively regulate AMPA receptor function or availability, thus preventing overactivation of AMPA receptors in the hippocampus. Our results are in contrast, however, with those of Wolf et al. (1995) who failed to detect changes in synaptic transmission in the presence of BEL. The reason for this discrepancy is not clear but could partly be attributed to the experimental approach we used to introduce the inhibitor into the neurons. The one important difference in our approach was the patch pipette injection of BEL directly into CA1 pyramidal cells rather than standard extracellular application deployed by Wolf and collaborators (1995). Our approach is likely to facilitate access of the iPLA2 inhibitor to its postsynaptic targets and could have prevented presynaptic effects that might mask postsynaptic actions during extracellular application of the drug. 
Altogether, the present results indicate that AMPA receptors are under the influence of endogenous lipase activities. Based mainly on data obtained from binding experiments on glutamate receptors, AMPA receptor conformation in synaptic membranes is believed to be sensitive to PLA2 enzymes (Massicotte et al., 1991; Massicotte, 2000). A particularly interesting aspect of this regulation is the demonstration that, depending of its activity, cPLA2 bidirectionally modulates AMPA receptor binding, with low activities generating a decline, and high activities, an augmentation in receptor affinity (Chabot et al., 1998). According to our previous studies, the CPLA2-induced decrease in AMPA receptor function is thought to result from the accumulation of 12-LO metabolites of AA within neurons (Normandin et al., 1996; Chabot et al., 1998). Experimental evidence suggests that metabolites generated by the 12-LO pathways have various cellular effects, including inhibition of $\mathrm{Ca}^{2+} /$ calmodulin-dependent protein kinase II (Piomelli et al., 1989; Piomelli and Greengard, 1991), a kinase known to regulate AMPA receptor activity (Hayashi et al., 2000). Considering these findings, one possible explanation of our results is that iPLA2 inhibition leads to a decrease in the formation of 12-LO metabolites and to an enhancement of $\mathrm{Ca}^{2+} /$ calmodulin-dependent protein kinase II activity, which could facilitate AMPA receptor-mediated function and synaptic transmission. In the present report, we failed to see any effect of the 12-LO inhibitor baicalein, which was introduced postsynaptically. This finding suggests that under iPLA2 inhibition, these metabolites do not contribute to the regulation of AMPA receptors. However, our patch-clamp experiments indicate that AMPA receptor responses can be upregulated by MK-886, raising the possibility that 5-LO (rather than 12-LO) metabolites may interact with AMPA receptor function. Regardless of which molecular mechanism is involved in this upregulation, an attractive hypothesis is that 5-LO metabolites might constitutively influence AMPA receptor availability or conformation through control of their interaction with the actin cytoskeleton. This scenario would be consistent with the recent report that AMPA receptor stabilization within synaptic membranes is under the influence of the actin cytoskeleton (Allison et al., 1998; Dingledine et al., 1999) and with the observation that 5-LO metabolites are essential for regulating actin networks in a number of cell types (Provost et al., 2001).

The biochemical demonstration that iPLA2 inhibition by BEL is also associated with enhancement of AMPA (but not NMDA) subunit immunoreactivity in brain homogenates indeed supports the notion that electrophysiological changes induced by iPLA2 inhibition could derive, at least, from modification in AMPA receptor conformation. The mechanisms by which BEL increases GluR1 immunoreactivity in brain slices are unknown. Considering the short time of incubation and the system utilized (i.e., rat brain sections), the augmented GluR immunoreactivity generated by iPLA2 inhibitors is possibly not due to heightened protein synthesis. Of course, it is well recognized that GluR subunits located in the postsynaptic density (as well as their chaperon proteins) can be regulated by a complex balance of phosphorylation/ dephosphorylation reactions (Song and Huganir, 2002). As mentioned previously, various studies have shown that AA metabolites generated by PLA2 enzymes can influence several types of protein kinases within neurons (Piomelli et al., 1989; Piomelli and Greengard, 1991), suggesting that the changes observed here can be mediated by AA metabolites acting on different kinases involved in phosphorylation of AMPA receptor complexes. Alternatively, there is increasing evidence that conformation, stabilization, interactions with PSD proteins, as well as antigenicity of GluR subunits are under the influence of calcium-dependent proteases (Bi et al., 1997, 1998), and it is thus possible that enhancement of GluR immunoreactivity resulting from iPLA2 inhibition might be linked to interactions with these enzymatic processes. In this regard, it will be of particular interest to determine to what extent iPLA2 or 5-LO inhibitors are capable of interfering with calciuminduced changes of AMPA receptor properties in rat brain sections.

Several recent studies indicate that iPLA2 enzymes may also play an important role in regulating multiple mammalian membranetrafficking events as well as endocytotic/exocytotic processes. For example, disruption of intracellular membrane-trafficking events that are recognized to depend on the formation of membrane tubules has been seen after treatment of cells with iPLA2 antagonists, including BEL (de Figueiredo et al., 1998; Kuroiwa et al., 2001). These trafficking processes comprise the membrane tubulemediated, stepwise reassembly of Golgi complexes into an interconnected juxtanuclear ribbon and the tubule-mediated Golgi-toendoplasmic reticulum retrograde trafficking that is produced by the fungal metabolite brefeldin A. On the other hand, BEL treatment is also known to interfere with membrane fusion events required during both endocytosis and exocytosis (Mayorga et al., 1993; Takuma and Ichida, 1997), providing additional support for a possible role of iPLA2 in membrane-trafficking events. Thus, in the present studies, it can be hypothesized that iPLA2 inhibition may modify trafficking events in a way that facilitates insertion and/or maintenance of AMPA receptors within synaptic membranes and, as a consequence, enhances AMPA receptor-mediated responses. This scenario would be entirely consistent with findings that synaptic AMPA receptor proteins are subjected to constitutive recycling along both exocytotic and endocytotic pathways (Carroll et al., 1999; Man et al., 2000; Broutman and Baudry, 2001). In this respect, future studies will have to be performed to assess whether iPLA2 inhibition influences the subcellular distribution of AMPA receptors in hippocampal neurons.

In conclusion, the present investigation has uncovered a new and unexpected role for PLA2 enzymes in neurons. Specifically, our results suggest that constitutive iPLA2 activities and perhaps generation of 5-LO metabolites of AA can limit AMPA receptormediated responses under basal conditions. Of course, this observation does not rule out the possibility that IPLA2 also contributes to AMPA receptor regulation during synaptic plasticity, as there are indications that PLA2 inhibitors interfere with both LTP and LTD (Massicotte, 2000). From a physiopathological perspective, the finding that iPLA2 activity is selectively decreased in a number of brain regions of patients who suffered from Alzheimer's disease (Ross et al., 1998) raises the interesting but speculative suggestion that AMPA receptor down-regulation through iPLA2 mechanisms might, in some manner, serve to limit excitotoxicity during aging. 


\section{Acknowledgments}

The authors thank Ovid Da Silva for editing this manuscript. This research was supported by grants from the Natural Sciences and Engineering Research Council (NSERC) of Canada (to G.M.).

\section{REFERENCES}

Allison DW, Gelfand VI, Spector I, Craig AM. 1998. Role of actin in anchoring postsynaptic receptors in cultured hippocampal neurons: differential attachment of NMDA versus AMPA receptors. J Neurosci 18:2423-2436.

Balsinde J, Dennis EA. 1997. Function and inhibition of intracellular calcium-independent phospholipase A2. J Biol Chem 272:1606916072.

Bi R, Bi X, Baudry M. 1997. Phosphorylation regulates calpain-mediated truncation of glutamate ionotropic receptor. Brain Res 797:154-158.

Bi X, Chen J, Dang S, Wenthold RJ, Tocco G, Baudry M. 1998. Characterization of calpain-mediated proteolysis of GluR1 subunits of alpha-amino-3-hydroxy-5-methylisoxazole-4-propionate receptor in rat brain. J Neurochem 68:1484-1494.

Broutman G, Baudry M. 2001. Involvement of the secretory pathway for AMPA receptors in NMDA-induced potentiation in hippocampus. J Neurosci 21:27-34.

Carroll RC, Beattie EC, Xia H, Luscher C, Altschuler Y, Nicoll RA, Malenka RC, von Zastrow M. 1999. Dynamin-dependent endocytosis of ionotropic glutamate receptors. Proc Natl Acad Sci USA 96: 14112-14117.

Chabot C, Gagne J, Giguere C, Bernard J, Baudry M, Massicotte G. 1998. Bidirectional modulation of AMPA receptor properties by exogenous phospholipase A2 in the hippocampus. Hippocampus 8:299-309.

de Figueiredo P, Drecktrah D, Katzenellenbogen JA, Strang M, Brown WJ. 1998. Evidence that phospholipase A2 activity is required for Golgi complex and trans Golgi network membrane tubulation. Proc Natl Acad Sci USA 95:8642-8647.

Dessen A. 2000. Structure and mechanism of human cytosolic phospholipase A(2). Biochim Biophys Acta 1488:40-47.

Dingledine R, Borges K, Bowie D, Traynelis SF. 1999. The glutamate receptor ion channels. Pharmacol Rev 51:7-61.

Fujita S, Ikegaya Y, Nishiyama N, Matsuki N. 2000. $\mathrm{Ca}^{2+}$-independent phospholipase A2 inhibitor impairs spatial memory of mice. Jpn J Pharmacol 83:277-278.

Hayashi Y, Shi SH, Esteban JA, Piccini A, Poncer JC, Malinow R. 2000. Driving AMPA receptors into synapses by LTP and CaMKII: requirement for GluR1 and PDZ domain interaction. Science 287:22622267.

Kuroiwa N, Nakamura M, Tagaya M, Takatsuki A. 2001. Arachidonyltrifluoromethy ketone, a phospholipase $\mathrm{A}(2)$ antagonist, induces dispersal of both Golgi stack- and trans Golgi network-resident proteins throughout the cytoplasm. Biochem Biophys Res Commun 281:582588 .
Laemmli UK. 1970. Cleavage of structural proteins during the assembly of the head of bacteriophage T4. Nature 227:680-685.

Man HY, Ju W, Ahmadian G, Wang YT. 2000. Intracellular trafficking of AMPA receptors in synaptic plasticity. Cell Mol Life Sci 57:15261534.

Massicotte G. 2000. Modification of glutamate receptors by phospholipase A2: its role in adaptive neural plasticity. Cell Mol Life Sci 57: 1542-1550.

Massicotte G, Vanderklish P, Lynch G, Baudry M. 1991. Modulation of DL-alpha-amino-3-hydroxy-5-methyl-4-isoxazolepropionic acid/quisqualate receptors by phospholipase A2: a necessary step in long-term potentiation? Proc Natl Acad Sci USA 88:1893-1897.

Mayorga LS, Colombo MI, Lennartz M, Brown EJ, Rahman KH, Weiss R, Lennon PJ, Stahl PD. 1993. Inhibition of endosome fusion by phospholipase A2 (PLA2) inhibitors points to a role for PLA2 in endocytosis. Proc Natl Acad Sci USA 90:10255-10259.

Normandin M, Gagne J, Bernard J, Elie R, Miceli D, Baudry M, Massicotte G. 1996. Involvement of the 12-lipoxygenase pathway of arachidonic acid metabolism in homosynaptic long-term depression of the rat hippocampus. Brain Res 730:40-46.

Piomelli D, Greengard P. 1991. Bidirectional control of phospholipase A2 activity by $\mathrm{Ca}^{2+} /$ calmodulin-dependent protein kinase II, cAMPdependent protein kinase, and casein kinase II. Proc Natl Acad Sci USA 88:6770-6774.

Piomelli D, Wang JK, Sihra TS, Nairn AC, Czernik AJ, Greengard P. 1989. Inhibition of $\mathrm{Ca}^{2+} /$ calmodulin-dependent protein kinase II by arachidonic acid and its metabolites. Proc Natl Acad Sci USA 86: 8550-8554.

Provost P, Doucet J, Hammarberg T, Gerisch G, Samuelsson B, Radmark O. 2001. 5-Lipoxygenase interacts with coactosin-like protein. J Biol Chem 276:16520-16527.

Ross BM, Moszczynska A, Erlich J, Kish SJ. 1998. Phospholipid-metabolizing enzymes in Alzheimer's disease: increased lysophospholipid acyltransferase activity and decreased phospholipase A2 activity. J Neurochem 70:786-793.

Ross BM, Turenne S, Moszczynska A, Warsh JJ, Kish SJ. 1999. Differential alteration of phospholipase A2 activities in brain of patients with schizophrenia. Brain Res 821:407-413.

Song I, Huganir RL. 2002. Regulation of AMPA receptors during synaptic plasticity. Trends Neurosci 25:578-588.

Takuma T, Ichida T. 1997. Role of $\mathrm{Ca}^{2+}$-independent phospholipase A2 in exocytosis of amylase from parotid acinar cells. J Biochem (Tokyo) 121:1018-1024.

Towbin H, Staehelin T, Gordon J. 1979. Electrophoretic transfer of proteins from polyacrylamide gels to nitrocellulose sheets: procedure and some applications. Proc Natl Acad Sci USA 76:4350-4354.

Winstead MV, Balsinde J, Dennis EA. 2000. Calcium-independent phospholipase $\mathrm{A}(2)$ : structure and function. Biochim Biophys Acta 1488: 28-39.

Wolf MJ, Izumi Y, Zorumski CF, Gross RW. 1995. Long-term potentiation requires activation of calcium-independent phospholipase A2. FEBS Lett 377:358-362.

Yang HC, Mosior M, Johnson CA, Chen Y, Dennis EA. 1999. Groupspecific assays that distinguish between the four major types of mammalian phospholipase A2. Anal Biochem 269:278-288. 